\title{
TASACIÓN DE DOS PINTURAS DE MURILLO Y ALONSO CANO DONADAS A LA COLEGIATA DE LA GRANJA DE SAN ILDEFONSO (SEGOVIA)
}

Se da a conocer un documento de tasación de dos pinturas donadas a la Real Colegiata de la Santísima Trinidad por don Nicolás de Rivera. Este documento inédito firmado en 1747 por el aposentador real Diego María Sani y el arquitecto Sempronio Subissati, fundamenta la tradicional atribución de las pinturas.

Palabras clave: Pintura española; Siglo XVII.

32 Antes de su importación a Nueva York estaba en la colección Reitlingen (Inglaterra) [WiLDENSTEIN, Nueva York, op. cit., 1962, No. 33]

33 Op. cit. 1963 , No. 10

34 Op. cit., 1976, p. 29.

35 Op. cit., 1980, p. 67-68. Véase también VAldelomar, R., "Díaz Padrón descubre la autoría de un lienzo anónimo de La Almoneda del siglo", $A B C$, 24-03-2002, p. 45; Idem, "Nada prueba que el cuadro sea de Van Oost, según Elliot y Brown", $A B C, 25-03-2002$, p. 45. El título del artículo de $A B C$ no responde a la contestación moderada de ELLIOT \& BROWN (que se lee fuera del titular) en espera del estudio detenido que aquí se publica.

${ }_{36}$ M. Rogers, “Two portraits by Van Dyck Identified”, The Burlington Magazine, April 1982, pp. 935-936.

37 JORDAN, op. cit., 1974, p. 28.

38 Chaipeita, P., "The Art of diplomacy", Country Life, 9 de mayo de 2002, p. 110

39 BrigstCKe, H., "El descubrimiento del arte español en Gran Bretaña", En torno a Velázquez. Pintura española del siglo de oro, The Apelles Collection, p. 5.

40 MÉndeZ RodrígueZ, L., "Acerca del supuesto naturalismo de la pintura española del siglo XVII con una nota sobre Las Meninas", Archivo Hispalense, año 2000, p. 13. Estima el autor extraño el tondo del marco del paisaje del fondo pero pensando que se trata de una obra española. Pero siendo de un pintor flamenco, es normal, op. cit., p. 19, piensa que es una alusión al hecho que transmite la escena

${ }^{41}$ Burke, M. B., op. cit., 1986, p. 7.

42 Op. cit., 2000, p. 52, No. 7.

43 Op. cit., 2002, p. 209, No. 29 (por A. Malcolm y M. BuRKe)

44 Henares CuÉllar, I., Alonso Cano. Espiritualidad y modernidad artística, Conferencia Museo del Prado, 20II-2002

AEA, LXXXII, 326, ABRIL-JUNIO 2009, 194-226, ISSN: 0004-0428 
An unpublished document (1747) is presented in which valuations are given for the paintings donated by the canon,

Nicolás de Rivera, to the Real Colegiata de la Santísima Trinidad. Signed by the royal chamberlain Diego María Sani and by the architect Sempronio Subissati, the document supports the traditional attributions of the paintings.

Key words: Spanish painting; 17th Century.

La construcción de la Real Capilla de La Granja de San Ildefonso se inició en 1720, al tiempo que las obras del Palacio y los Jardines, con el claro propósito de servir de enterramiento a su fundador, Felipe V. La consagración del templo, con la advocación de la Santísima Trinidad, tuvo lugar el 22 de diciembre de 1723. A requerimiento de su patrono adquirió, un año después, el rango de Colegiata por Bula expedida en Roma por el papa Benedicto XIII. Desde entonces, y bajo el patrocinio de los sucesivos monarcas de la dinastía borbónica, los muros y bóvedas de su iglesia, así como el resto de dependencias anejas, se fueron cubriendo de pinturas y frescos vinculados a los nombres de Maella y Francisco Bayeu, digno complemento del panteón real, trazado por el italiano Sempronio Subissati.

De entre las primeras pinturas que ornaron el conjunto abacial existen dos que vienen siendo tradicionalmente atribuidas a Murillo y Alonso Cano por los diferentes cronistas del Real Sitio ${ }^{1}$. Se trata de un Cristo crucificado (fig. 1), asignado al maestro sevillano, y una Inmaculada (fig. 2), atribuida al versátil granadino, situadas ambas sobre la cajonería de la sacristía y recogidas en los diferentes inventarios de la Colegiata ${ }^{2}$. Un documento inédito, custodiado en el Archivo de la Colegiata y que damos a conocer a continuación, fundamenta esta secular atribución. Se trata de la tasación de estas dos pinturas, donadas al cabildo en sesión de 13 de enero de $1747^{3}$ por don Nicolás de Ribera 4 , realizada por el aposentador real Domingo María Sani ${ }^{5}$ y el arquitecto Sempronio Subissati6:

\footnotetext{
1 "Están colocadas en esta sacristia dos pinturas que representan a Cristo en la cruz y Ntra. Señora de la Concepcion, de Murillo y Cano, regaladas por D. Nicolas Rivera, presidente que fue de este Cabildo; debajo de las cuales están situados los cajones en que se guardan los ornamentos, que sirven diariamente para los divinos oficios" (Fagoaga, José de; Muñico, Tomás: Descripción de los Reales Sitios de San Ildefonso, Valsain y Riofrío. Hechos célebres ocurridos en ellos, Imprenta de D. Eduardo Baeza, Segovia, 1845, pp. 68-69); "Encima [de la cajonería] se ven dos pinturas, que pasan por ser originales de Murillo y Alonso Cano, y representan la Concepción y Cristo en la cruz" (Breñosa, Rafael; Castellarnau, Joaquín M. a de: Guía y descripción del Real Sitio de San Ildefonso, Tip. de los Sucesores de Rivadeneyra, Madrid, 1884, p. 139); “... dos pinturas que se atribuyen a Alonso Cano y Murillo, representativas de Cristo en la cruz y la Concepción" (COSTA y GARCía, José: Guía del Real Sitio de San Ildefonso (La Granja), Segovia, 1918, p. 69).

2 Archivo de la Colegiata de la Santísima Trinidad (en adelante, ACST). Inventarios años 1816, 1836, 1844, 1850, 1857,1864 y 1894.

3 "Asi mismo dijo el Sr. Presidente D. Nicolas de Ribera que hazia donación al Cabildo de dos ymagenes una de un Santisimo Christo de mano de Murillo tasado en tres mil reales de vellon y otro de Nuestra Señora de la Concepción de mano del razionero Cano tasada en mil ochocientos reales de vellon, ambos por los pintores de Su Majestad Don Domingo Maria Sani y Don Sempronio Subissati, de que daria la tasa al Cabildo". ACST. Libro Primero de Acuerdos. Cabildo Extraordinario de 13 de enero de 1747. Folio 306 y ss.

${ }^{4}$ Don Nicolás Miguel de Ribera fue nombrado Canónigo Lectoral el 30 de diciembre de 1725. Vicario General desde 1742, muere el 21 de julio de 1748. ACST. Libro Primero de Acuerdo del Cabildo. 1725-1750.

${ }^{5}$ El artista italiano Domingo María Sani (1690-1773) llegó España en 1721 para auxiliar a su maestro, Andrea Procaccini, en la decoración pictórica del Palacio de La Granja. Desempeñó los cargos de aposentador del Real Sitio y jefe de la furriela de la Reina viuda (Archivo Histórico Provincial de Segovia. Protocolo n. ${ }^{\circ}$ 3563, fol. 117 y ss.). Para una biografía de Sani, véase UrRea FernáNDEZ, Jesús: La pintura italiana del siglo XVIII en España, Valladolid, 1977, pp. 199-214.

${ }^{6}$ Arquitecto y pintor, Sempronio Subissati (Urbino, 1680-Madrid, 1758) fue llamado por Andrea Procaccini para ayudarle en sus encargos regios, llegando a España en 1722. Como pintor colaboró en la decoración al fresco de las habitaciones del Palacio de La Granja. A la muerte de Proccacini (1734), la dirección de las obras del palacio recayó en él y en Domingo María Sani, supervisados desde la Corte por el marqués de Scotti. Entre sus obras cabe destacar la construcción del patio de la Herradura y las trazas del sepulcro de Felipe V y de su mujer doña Isabel de Farnesio.
} 


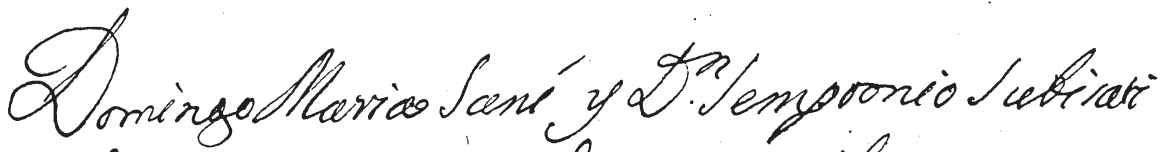
becimos, que acienfo reconocido en casade D.' An' Nicolas de Ricuera, Canonigo Lectoral de estar Ml- Ynigigne Yglesice, dos asinteras quelanena raporesenita un tanto ersito $y$ res ninos al pie, de mun de Murilo, dumedile de quarro pies escasos de atro y mes escasos de anche, he marro derado con dos ordenes de rallas, wala bes mil PSP 2 el orro dela misma ne sidary marco, que repres enta una con cención con quatio querobines celoriè, Remano del Racionero cano, uale mil

- ochocientes MSUn quefcoracensor guerecido Jer Lu calor, lo firmamos hor

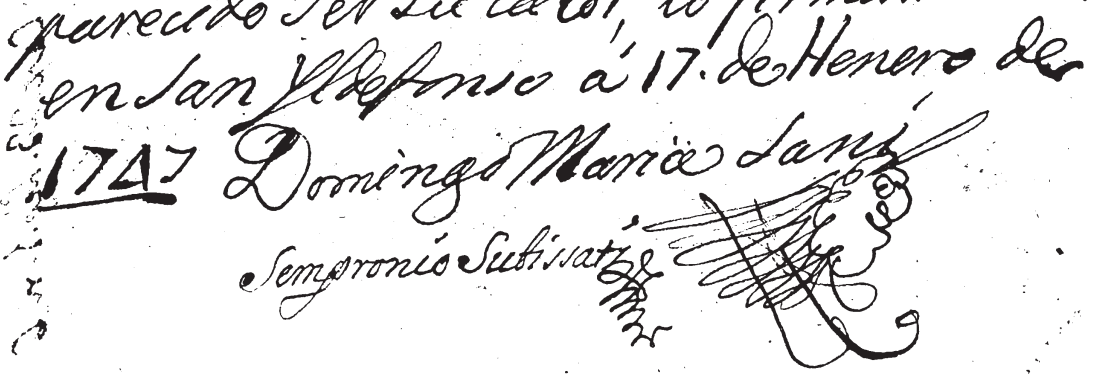

Archivo Colegiata Santísima Trinidad. Caja 23, leg. 1, núm. 6.

Domingo Maria Saní y D. ${ }^{n}$ Sempronio Subisati decimos, que auiendo reconocido en casa del D. ${ }^{\text {or }} D .{ }^{n}$ Nicolás de Rivera, Canonigo Lectoral de esta R. ${ }^{l}$ ynsigne Yglesia, dos pinturas que la una representa un Santo Cristo y tres niños al pie, de mano de Murillo, su medida de quatro pies escasos de alto y tres escasos de ancho, su marco dorado con dos ordenes de talla, vale tres mil $R^{s} V^{n}$ y el otro de la misma medida y marco, que representa una Concepcion con quatro querobines a los pies de mano del Racionero Cano, vale mil ochocientos $R .^{s} V^{n}$ que por auernos parecido ser su valor, lo firmamos hoy en San Yldefonso á 17. de Henero de 1747.

Firmado: Domingo Maria Saní/Sempronio Subissati 


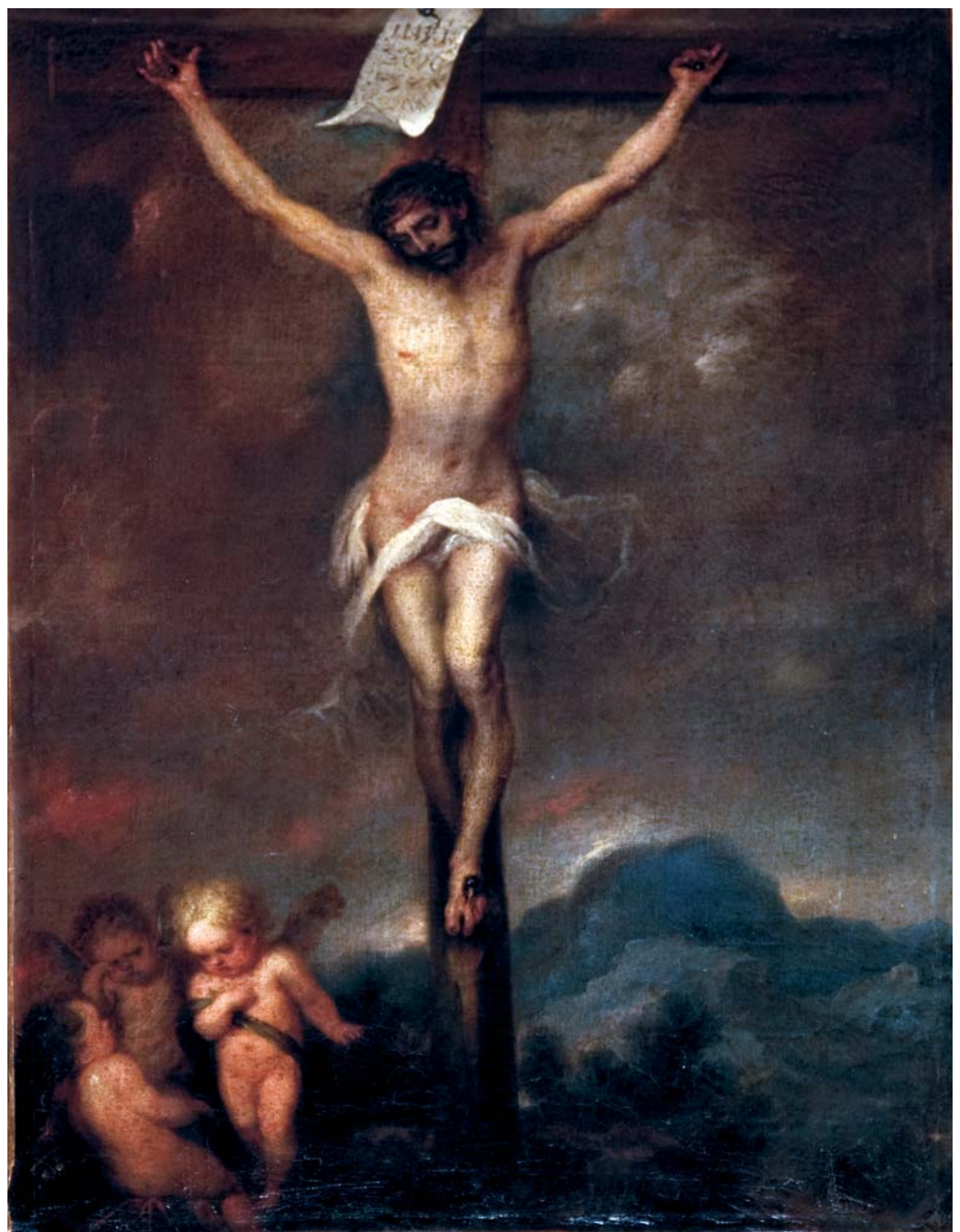

Fig. 1. Bartolomé Esteban Murillo (atrib.). Cristo crucificado. Óleo sobre lienzo. $115 \times 80 \mathrm{~cm}$. Real Colegiata de la Santísima Trinidad. La Granja de San Ildefonso (Segovia).

Con motivo de la inclusión de la pintura que representa a Cristo crucificado en el ciclo de exposiciones Las Edades del Hombre ("El árbol de la vida", Segovia, 2003), E. Valdivieso consideró insostenible la opinión tradicional de que se trata de un original de Murillo para situarla en el círculo del pintor Atanasio Bocanegra ${ }^{7}$, seguidor de Cano en Granada. En su ficha catalográfica argumenta el profesor que de haberse debido al artista sevillano hubiera sido mencionada

7 Valdivieso, Enrique: "Cristo crucificado", en El Árbol de la Vida (catálogo de la exposición Las Edades del Hombre, catedral de Segovia, mayo-noviembre de 2003), ficha n. ${ }^{\circ}$ 14, pp. 194-195. 


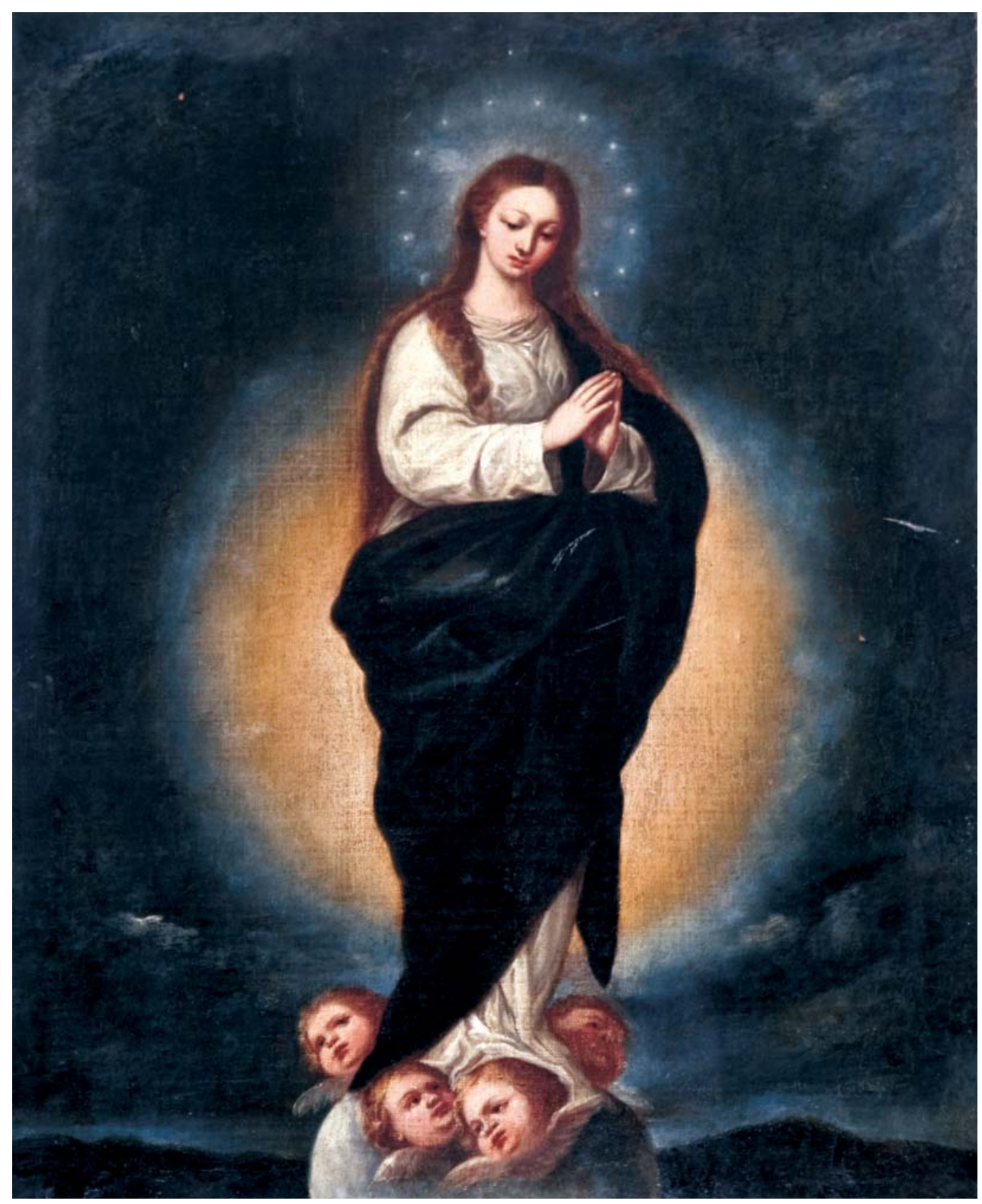

Fig. 2. Alonso Cano (atrib.). Inmaculada Concepción. Óleo sobre lienzo. $115 \times 80 \mathrm{~cm}$. Real Colegiata de la Santísima Trinidad. La Granja de San Ildefonso (Segovia).

y considerada en la exhaustiva monografía que le dedicó en 1981 don Diego Angulo. Aun con toda la consideración que merece una opinión tan autorizada, esta última afirmación requiere una puntualización. En la citada obra monumental, y catalogada en el apartado de obras discutibles con el número 732, incluye Angulo una Concepción en La Colegiata mencionada como original de Murillo por R. Breñosa en su Guía del Real Sitio de San Ildefonso (1884), para señalar a continuación: "No ha podido ser localizada ninguna Concepción que pueda relacionarse con el 


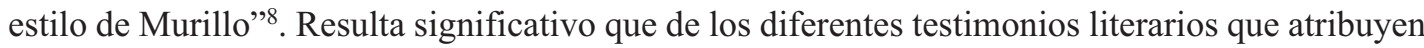
estas dos obras a Murillo y Alonso Cano cite Angulo únicamente aquél en el que la atribución respectiva de las pinturas aparece cambiada o, cuando menos, poco clara, al afirmar literalmente el cronista: "Encima [de la cajonería] se ven dos pinturas, que pasan por ser originales de Murillo y Alonso Cano, y representan la Concepción y Cristo en la cruz"9. Expresado de esta forma, se infiere que la obra que se atribuye a Murillo es la Concepción -y no el Cristo crucificado-, tal y como debió de ocurrirle a don Diego Angulo.

Resulta extraño, por otra parte, que el investigador norteamericano H. Wethey, experto indiscutible en Alonso Cano ${ }^{10}$, no haya hecho la menor mención en sus trabajos a la Concepción -ni tan siquiera en el apartado de atribuciones dudosas-, cuyos rasgos formales, por lo demás, pueden reconocerse en algunas versiones del mismo tema debidas al racionero granadino.

Aun con todas las reservas que implica un documento como el que damos a conocer, pero ante la duda razonable que plantea la pretendida autoría de ambos cuadros, consideramos que debería reconsiderarse su estudio. Quede, no obstante, para los expertos en su pintura la crítica de estilo y para los técnicos el dictamen final acerca de la controvertida autoría de estas dos pinturas que, desposeídas de sus marcos originales y oscurecidas por la oxidación de sus barnices, permanecen en su primitivo emplazamiento. Hasta entonces, una limpieza y eliminación de repintes podría clarificar algo más las cosas.

POMPEYO MARTÍN PÉREZ Francisco Egaña CASARIEGo

\footnotetext{
${ }^{8}$ ANGUlo, Diego: Murillo, Espasa Calpe, S. A., Madrid, 1981, t. II, p. 366.

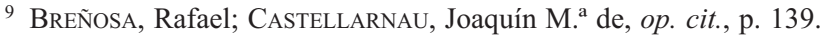

10 Wethey, Harold E.: Alonso Cano, pintor, Instituto Diego Velázquez, CSIC, Madrid, 1958, e Id.: Alonso Cano. Pintor, escultor y arquitecto, Alianza Editorial, Madrid, 1983.
} 